\title{
Strong convergence of iterative algorithms for the split equality problem
}

Luo Yi Shi ${ }^{1}$, Rudong Chen ${ }^{1 *}$ and Yujing $\mathrm{Wu}^{2}$

\section{${ }^{*}$ Correspondence:}

chenrd@tjpu.edu.cn

'Department of Mathematics,

Tianjin Polytechnic University,

Tianjin, 300387, P.R. China

Full list of author information is

available at the end of the article

\begin{abstract}
Let $H_{1}, H_{2}, H_{3}$ be real Hilbert spaces, $C \subseteq H_{1}, Q \subseteq H_{2}$ be two nonempty closed convex sets, and let $A: H_{1} \rightarrow H_{3}, B: H_{2} \rightarrow H_{3}$ be two bounded linear operators. The split equality problem (SEP) is finding $x \in C, y \in Q$ such that $A x=B y$. Recently, Moudafi has presented the ACQA algorithm and the RACQA algorithm to solve SEP. However, the two algorithms are weakly convergent. It is therefore the aim of this paper to construct new algorithms for SEP so that strong convergence is guaranteed. Firstly, we define the concept of the minimal norm solution of SEP. Using Tychonov regularization, we introduce two methods to get such a minimal norm solution. And then, we introduce two algorithms which are viewed as modifications of Moudafi's ACQA, RACQA algorithms and KM-CQ algorithm, respectively, and converge strongly to a solution of SEP. More importantly, the modifications of Moudafi's ACQA, RACQA algorithms converge strongly to the minimal norm solution of SEP. At last, we introduce some other algorithms which converge strongly to a solution of SEP.
\end{abstract}

Keywords: split equality problem; iterative algorithms; converge strongly

\section{Introduction and preliminaries}

Let $C$ and $Q$ be nonempty closed convex subsets of real Hilbert spaces $H_{1}$ and $H_{2}$, respectively, and let $A: H_{1} \rightarrow H_{2}$ be a bounded linear operator. The splitfeasibility problem (SFP) is to find a point $x$ satisfying the property

$$
x \in C, \quad A x \in Q
$$

if such a point exists. SFP was first introduced by Censor and Elfving [1], which has attracted many authors' attention due to its application in signal processing [1]. Various algorithms have been invented to solve it (see [2-7]).

Recently, Moudafi [8] proposed a new split equality problem (SEP): Let $H_{1}, H_{2}, H_{3}$ be real Hilbert spaces, $C \subseteq H_{1}, Q \subseteq H_{2}$ be two nonempty closed convex sets, and let $A: H_{1} \rightarrow H_{3}$, $B: H_{2} \rightarrow H_{3}$ be two bounded linear operators. Find $x \in C, y \in Q$ satisfying

$$
A x=B y .
$$

When $B=I$, SEP reduces to the well-known SFP. In the paper [8], Moudafi gave the following iterative algorithms for solving the split equality problem.

( 2014 Shi et al.; licensee Springer. This is an Open Access article distributed under the terms of the Creative Commons Attribution License (http://creativecommons.org/licenses/by/2.0), which permits unrestricted use, distribution, and reproduction in any medium, provided the original work is properly cited. 
Alternating CQ-algorithm (ACQA):

$$
\left\{\begin{array}{l}
x_{k+1}=P_{C}\left(x_{k}-\gamma_{k} A^{*}\left(A x_{k}-B y_{k}\right)\right) ; \\
y_{k+1}=P_{Q}\left(y_{k}+\gamma_{k} B^{*}\left(A x_{k+1}-B y_{k}\right)\right) .
\end{array}\right.
$$

Relaxed alternating CQ-algorithm (RACQA):

$$
\left\{\begin{array}{l}
x_{k+1}=P_{C_{k}}\left(x_{k}-\gamma A^{*}\left(A x_{k}-B y_{k}\right)\right) ; \\
y_{k+1}=P_{Q_{k}}\left(y_{k}+\beta B^{*}\left(A x_{k+1}-B y_{k}\right)\right) .
\end{array}\right.
$$

However, the above algorithms converge weakly to a solution of SEP.

It is therefore the aim of this paper to construct a new algorithm for SEP so that strong convergence is guaranteed. The paper is organized as follows. In Section 2, we define the concept of the minimal norm solution of SEP (1.1). Using Tychonov regularization, we obtain a net of solutions for some minimization problem approximating such minimal norm solutions (see Theorem 2.4). In Section 3, we introduce an algorithm which is viewed as a modification of Moudafi's ACQA and RACQA algorithms; and we prove the strong convergence of the algorithm, more importantly, its limit is the minimum-norm solution of SEP (1.1) (see Theorem 3.2). In Section 4, we introduce a KM-CQ-like iterative algorithm which converges strongly to a solution of SEP (1.1) (see Theorem 4.3). In Section 5, we introduce some other iterative algorithms which converge strongly to a solution of SEP (1.1).

Throughout the rest of this paper, $I$ denotes the identity operator on a Hilbert space $H$, Fix $(T)$ is the set of the fixed points of an operator $T$ and $\nabla f$ is the gradient of the functional $f: H \rightarrow R$. An operator $T$ on a Hilbert space $H$ is nonexpansive if, for each $x$ and $y$ in $H$, $\|T x-T y\| \leq\|x-y\| . T$ is said to be averaged if there exists $0<\alpha<1$ and a nonexpansive operator $N$ such that $T=(1-\alpha) I+\alpha N$.

Let $P_{S}$ denote the projection from $H$ onto a nonempty closed convex subset $S$ of $H$; that is,

$$
P_{S}(w)=\min _{x \in S}\|x-w\|
$$

It is well known that $P_{S}(w)$ is characterized by the inequality

$$
\left\langle w-P_{S}(w), x-P_{S}(w\rangle \leq 0, \quad \forall x \in S,\right.
$$

and $P_{S}$ is nonexpansive and averaged.

We now collect some elementary facts which will be used in the proofs of our main results.

Lemma 1.1 $[9,10]$ Let $X$ be a Banach space, $C$ be a closed convex subset of $X$, and $T: C \rightarrow$ $C$ be a nonexpansive mapping with $\operatorname{Fix}(T) \neq \emptyset$. If $\left\{x_{n}\right\}$ is a sequence in $C$ weakly converging to $x$ and if $\left\{(I-T) x_{n}\right\}$ converges strongly to $y$, then $(I-T) x=y$.

Lemma 1.2 [11] Let $\left\{s_{n}\right\}$ be a sequence of nonnegative real numbers, $\left\{\alpha_{n}\right\}$ be a sequence of real numbers in $[0,1]$ with $\sum_{n=1}^{\infty} \alpha_{n}=\infty,\left\{u_{n}\right\}$ be a sequence of nonnegative real numbers 
with $\sum_{n=1}^{\infty} u_{n}<\infty$, and $\left\{t_{n}\right\}$ be a sequence of real numbers with $\limsup _{n} t_{n} \leq 0$. Suppose that

$$
s_{n+1}=\left(1-\alpha_{n}\right) s_{n}+\alpha_{n} t_{n}+u_{n}, \quad \forall n \in N
$$

Then $\lim _{n \rightarrow \infty} s_{n}=0$.

Lemma 1.3 [12] Let $\left\{w_{n}\right\},\left\{z_{n}\right\}$ be bounded sequences in a Banach space, and let $\left\{\beta_{n}\right\}$ be a sequence in $[0,1]$ which satisfies the following condition:

$$
0<\liminf _{n \rightarrow \infty} \beta_{n} \leq \limsup _{n \rightarrow \infty} \beta_{n}<1 .
$$

Suppose that $w_{n+1}=\left(1-\beta_{n}\right) w_{n}+\beta_{n} z_{n}$ and $\lim _{\sup } \rightarrow \infty\left\|z_{n+1}-z_{n}\right\|-\left\|w_{n+1}-w_{n}\right\| \leq 0$, then $\lim _{n \rightarrow \infty}\left\|z_{n}-w_{n}\right\|=0$.

Lemma 1.4 [13] Let $f$ be a convex and differentiable functional, and let $C$ be a closed convex subset of $H$. Then $x \in C$ is a solution of the problem

$$
\min _{x \in C} f(x)
$$

if and only if $x \in C$ satisfies the following optimality condition:

$$
\langle\nabla f(x), v-x\rangle \geq 0, \quad \forall v \in C
$$

Moreover, iff is, in addition, strictly convex and coercive, then the minimization problem has a unique solution.

Lemma 1.5 [3] Let $A$ and $B$ be averaged operators and suppose that $\operatorname{Fix}(A) \cap \operatorname{Fix}(B)$ is nonempty. Then $\operatorname{Fix}(A) \cap \operatorname{Fix}(B)=\operatorname{Fix}(A B)=\operatorname{Fix}(B A)$.

\section{Minimum-norm solution of SEP}

In this section, we define the concept of the minimal norm solution of SEP (1.1). Using Tychonov regularization, we obtain a net of solutions for some minimization problem approximating such minimal norm solutions.

We use $\Gamma$ to denote the solution set of SEP, i.e.,

$$
\Gamma=\left\{(x, y) \in H_{1} \times H_{2}, A x=B y, x \in C, y \in Q\right\}
$$

and assume the consistency of SEP so that $\Gamma$ is closed, convex and nonempty.

Let $S=C \times Q$ in $H=H_{1} \times H_{2}$, define $G: H \rightarrow H_{3}$ by $G=[A,-B]$, then $G^{*} G: H \rightarrow H$ has the matrix form

$$
G^{*} G=\left[\begin{array}{cc}
A^{*} A & -A^{*} B \\
-B^{*} A & B^{*} B
\end{array}\right] .
$$

The original problem can now be reformulated as finding $w=(x, y) \in S$ with $G w=0$, or, more generally, minimizing the function $\|G w\|$ over $w \in S$. Therefore solving SEP (1.1) is 
equivalent to solving the following minimization problem:

$$
\min _{w \in S} f(w)=\frac{1}{2}\|G w\|^{2},
$$

which is in general ill-posed. A classical way to deal with such a possibly ill-posed problem is the well-known Tychonov regularization, which approximates a solution of problem (2.1) by the unique minimizer of the regularized problem:

$$
\min _{w \in S} f_{\alpha}(w)=\frac{1}{2}\|G w\|^{2}+\frac{1}{2} \alpha\|w\|^{2},
$$

where $\alpha>0$ is the regularization parameter. Denote by $w_{\alpha}=\left(x_{\alpha}, y_{\alpha}\right)$ the unique solution of (2.2).

Proposition 2.1 For any $\alpha>0$, the solution $w_{\alpha}=\left(x_{\alpha}, y_{\alpha}\right)$ of $(2.2)$ is uniquely defined. Moreover, $w_{\alpha}=\left(x_{\alpha}, y_{\alpha}\right)$ is characterized by the inequality

$$
\left\langle G^{*} G w_{\alpha}+\alpha w_{\alpha}, w-w_{\alpha}\right\rangle \geq 0, \quad \forall w \in S
$$

i.e.,

$$
\left\langle A^{*}\left(A x_{\alpha}-B y_{\alpha}\right)+\alpha x_{\alpha}, x-x_{\alpha}\right\rangle \geq 0, \quad \forall x \in C
$$

and

$$
\left\langle-B^{*}\left(A x_{\alpha}-B y_{\alpha}\right)+\alpha y_{\alpha}, y-y_{\alpha}\right\rangle \geq 0, \quad \forall y \in Q
$$

Proof It is well known that $f(w)=\frac{1}{2}\|G w\|^{2}$ is convex and differentiable with gradient $\nabla f(w)=G^{*} G w, f_{\alpha}(w)=f(w)+\frac{1}{2} \alpha\|w\|^{2}$. We can get that $f_{\alpha}$ is strictly convex, coercive, and differentiable with gradient

$$
\nabla f_{\alpha}(w)=G^{*} G w+\alpha w .
$$

It follows from Lemma 1.4 that $w_{\alpha}$ is characterized by the inequality

$$
\left\langle G^{*} G w_{\alpha}+\alpha w_{\alpha}, w-w_{\alpha}\right\rangle \geq 0, \quad \forall w \in S .
$$

Note that $\{(x, 0), x \in C\} \subseteq S,\{(0, y), y \in Q\} \subseteq S$, adding up (2.3), we can get that

$$
\left\langle A^{*}\left(A x_{\alpha}-B y_{\alpha}\right)+\alpha x_{\alpha}, x-x_{\alpha}\right\rangle \geq 0, \quad \forall x \in C ;
$$

and

$$
\left\langle-B^{*}\left(A x_{\alpha}-B y_{\alpha}\right)+\alpha y_{\alpha}, y-y_{\alpha}\right\rangle \geq 0, \quad \forall y \in Q .
$$

Definition 2.2 An element $\tilde{w}=(\tilde{x}, \tilde{y}) \in \Gamma$ is said to be the minimal norm solution of SEP (1.1) if $\|\tilde{w}\|=\inf _{w \in \Gamma}\|w\|$. 
The next result collects some useful properties of $\left\{w_{\alpha}\right\}$, the unique solution of (2.2).

Proposition 2.3 Let $w_{\alpha}$ be given as the unique solution of (2.2). Then the following assertions hold.

(i) $\left\|w_{\alpha}\right\|$ is decreasing for $\alpha \in(0, \infty)$.

(ii) $\alpha \mapsto w_{\alpha}$ defines a continuous curve from $(0, \infty)$ to $H$.

Proof Let $\alpha>\beta>0$; since $w_{\alpha}$ and $w_{\beta}$ are the unique minimizers of $f_{\alpha}$ and $f_{\beta}$, respectively, we can get that

$$
\begin{aligned}
& \frac{1}{2}\left\|G w_{\alpha}\right\|^{2}+\frac{1}{2} \alpha\left\|w_{\alpha}\right\|^{2} \leq \frac{1}{2}\left\|G w_{\beta}\right\|^{2}+\frac{1}{2} \alpha\left\|w_{\beta}\right\|^{2}, \\
& \frac{1}{2}\left\|G w_{\beta}\right\|^{2}+\frac{1}{2} \beta\left\|w_{\beta}\right\|^{2} \leq \frac{1}{2}\left\|G w_{\alpha}\right\|^{2}+\frac{1}{2} \beta\left\|w_{\alpha}\right\|^{2} .
\end{aligned}
$$

Hence we can obtain that $\left\|w_{\alpha}\right\| \leq\left\|w_{\beta}\right\|$. That is to say, $\left\|w_{\alpha}\right\|$ is decreasing for $\alpha \in(0, \infty)$.

By Proposition 2.1, we have

$$
\left\langle G^{*} G w_{\alpha}+\alpha w_{\alpha}, w_{\beta}-w_{\alpha}\right\rangle \geq 0
$$

and

$$
\left\langle G^{*} G w_{\beta}+\beta w_{\beta}, w_{\alpha}-w_{\beta}\right\rangle \geq 0 .
$$

It follows that

$$
\left\langle w_{\alpha}-w_{\beta}, \alpha w_{\alpha}-\beta w_{\beta}\right\rangle \leq\left\langle w_{\alpha}-w_{\beta}, G^{*} G\left(w_{\beta}-w_{\alpha}\right)\right\rangle \leq 0 \text {. }
$$

Hence

$$
\alpha\left\|w_{\alpha}-w_{\beta}\right\| \leq(\alpha-\beta)\left\langle w_{\alpha}-w_{\beta}, w_{\beta}\right\rangle .
$$

It turns out that

$$
\left\|w_{\alpha}-w_{\beta}\right\|^{2} \leq \frac{|\alpha-\beta|}{\alpha}\left\|w_{\beta}\right\| .
$$

Thus $\alpha \mapsto w_{\alpha}$ defines a continuous curve from $(0, \infty)$ to $H$.

Theorem 2.4 Let $w_{\alpha}$ be given as the unique solution of (2.2). Then $w_{\alpha}$ converges strongly as $\alpha \rightarrow 0$ to the minimum-norm solution $\tilde{w}$ of SEP (1.1).

Proof For any $0<\alpha<\infty, w_{\alpha}$ is given as (2.2), it follows that

$$
\frac{1}{2}\left\|G w_{\alpha}\right\|^{2}+\frac{1}{2} \alpha\left\|w_{\alpha}\right\|^{2} \leq \frac{1}{2}\|G \tilde{w}\|^{2}+\frac{1}{2} \alpha\|\tilde{w}\|^{2} .
$$

Since $\tilde{w} \in \Gamma$ is a solution for SEP, we get

$$
\frac{1}{2}\left\|G w_{\alpha}\right\|^{2}+\frac{1}{2} \alpha\left\|w_{\alpha}\right\|^{2} \leq \frac{1}{2} \alpha\|\tilde{w}\|^{2} .
$$

Hence, $\left\|w_{\alpha}\right\| \leq\|\tilde{w}\|$ for all $\alpha>0$. That is to say, $\left\{w_{\alpha}\right\}$ is a bounded net in $H=H_{1} \times H_{2}$. 
For any sequence $\left\{\alpha_{n}\right\}$ such that $\lim _{n} \alpha_{n}=0$, let $w_{\alpha_{n}}$ be abbreviated as $w_{n}$. All we need to prove is that $\left\{w_{n}\right\}$ contains a subsequence converging strongly to $\tilde{w}$.

Indeed $\left\{w_{n}\right\}$ is bounded and $S$ is bounded convex. By passing to a subsequence if necessary, we may assume that $\left\{w_{n}\right\}$ converges weakly to a point $\hat{w} \in S$. By Proposition 2.1, we get that

$$
\left\langle G^{*} G w_{n}+\alpha_{n} w_{n}, \tilde{w}-w_{n}\right\rangle \geq 0 .
$$

It follows that

$$
\left\langle G w_{n}, G \tilde{w}-G w_{n}\right\rangle \geq \alpha_{n}\left\langle w_{n}, w_{n}-\tilde{w}\right\rangle .
$$

Since $\tilde{w} \in \Gamma$, it turns out that

$$
\left\langle G w_{n},-G w_{n}\right\rangle \geq \alpha_{n}\left\langle w_{n}, w_{n}-\tilde{w}\right\rangle .
$$

Using $\left\|w_{n}\right\| \leq\|\tilde{w}\|$, we can get that

$$
\left\|G w_{n}\right\| \leq 2 \alpha_{n}\|\tilde{w}\| \rightarrow 0 .
$$

Furthermore, note that $\left\{w_{n}\right\}$ converges weakly to a point $\hat{w} \in S$, then $\left\{G w_{n}\right\}$ converges weakly to $G \hat{w}$. It follows that $G \hat{w}=0$, i.e., $\hat{w} \in \Gamma$.

At last, we prove that $\hat{w}=\tilde{w}$ and this finishes the proof.

Since $\left\{w_{n}\right\}$ converges weakly to $\hat{w}$ and $\left\|w_{n}\right\| \leq\|\tilde{w}\|$, we can get that

$$
\hat{w} \leq \liminf _{n}\left\|w_{n}\right\| \leq\|\tilde{w}\|=\min \{\|w\|: w \in \Gamma\} .
$$

This shows that $\hat{w}$ is also a point in $\Gamma$ which assumes a minimum norm. Due to the uniqueness of a minimum-norm element, we obtain $\hat{w}=\tilde{w}$.

Finally, we introduce another method to get the minimum-norm solution of SEP.

Lemma 2.5 Let $T=I-\gamma G^{*} G$, where $0<\gamma<2 / \rho\left(G^{*} G\right)$ with $\rho\left(G^{*} G\right)$ being the spectral radius of the self-adjoint operator $G^{*} G$ on $H$. Then we have the following:

(1) $\|T\| \leq 1$ (i.e., $T$ is nonexpansive) and averaged;

(2) $\operatorname{Fix}(T)=\{(x, y) \in H, A x=B y\}, \operatorname{Fix}\left(P_{S} T\right)=\operatorname{Fix}\left(P_{S}\right) \cap \operatorname{Fix}(T)=\Gamma$;

(3) $w \in \operatorname{Fix}\left(P_{S} T\right)$ if and only if $w$ is a solution of the variational inequality $\left\langle G^{*} G w, v-w\right\rangle \geq 0, \forall v \in S$.

Proof (1) It is easily proved that $\|T\| \leq 1$, we only prove that $T=I-\gamma G^{*} G$ is averaged. Indeed, choose $0<\beta<1$ such that $\gamma /(1-\beta)<2 / \rho\left(G^{*} G\right)$, then $T=I-\gamma G^{*} G=\beta I+(1-\beta) V$, where $V=I-\gamma /(1-\beta) G^{*} G$ is a nonexpansive mapping. That is to say, $T$ is averaged.

(2) If $w \in\{(x, y) \in H, A x=B y\}$, it is obvious that $w \in \operatorname{Fix}(T)$. Conversely, assume that $w \in \operatorname{Fix}(T)$, we have $w=w-\gamma G^{*} G w$, hence $\gamma G^{*} G w=0$, then $\|G w\|^{2}=\left\langle G^{*} G w, w\right\rangle=0$, we get that $w \in\{(x, y) \in H, A x=B y\}$. This leads to $\operatorname{Fix}(T)=\{(x, y) \in H, A x=B y\}$. 
Now we prove $\operatorname{Fix}\left(P_{S} T\right)=\operatorname{Fix}\left(P_{S}\right) \cap \operatorname{Fix}(T)=\Gamma$. By $\operatorname{Fix}(T)=\{(x, y) \in H, A x=B y\}$, $\operatorname{Fix}\left(P_{S}\right) \cap \operatorname{Fix}(T)=\Gamma$ is obvious. On the other hand, since $\operatorname{Fix}\left(P_{S}\right) \cap \operatorname{Fix}(T)=\Gamma \neq \emptyset$, and both $P_{S}$ and $T$ are averaged, from Lemma 1.5, we have $\operatorname{Fix}\left(P_{S} T\right)=\operatorname{Fix}\left(P_{S}\right) \cap \operatorname{Fix}(T)$.

(3)

$$
\begin{aligned}
\left\langle G^{*} G w, v-w\right\rangle \geq 0, \quad \forall v \in S & \Leftrightarrow \quad\left\langle w-\left(w-\gamma G^{*} G w\right), v-w\right\rangle \geq 0, \quad \forall v \in S \\
& \Leftrightarrow \quad w=P_{S}\left(w-\gamma G^{*} G w\right) \\
& \Leftrightarrow \quad w \in \operatorname{Fix}\left(P_{S} T\right) .
\end{aligned}
$$

Remark 2.6 Take a constant $\gamma$ such that $0<\gamma<2 / \rho\left(G^{*} G\right)$ with $\rho\left(G^{*} G\right)$ being the spectral radius of the self-adjoint operator $G^{*} G$. For $\alpha \in\left(0, \frac{2-\gamma\left\|G^{*} G\right\|}{2 \gamma}\right)$, we define a mapping

$$
W_{\alpha}(w):=P_{S}\left[(1-\alpha \gamma) I-\gamma G^{*} G\right] w .
$$

It is easy to check that $W_{\alpha}$ is contractive. So, $W_{\alpha}$ has a unique fixed point denoted by $w_{\alpha}$, that is,

$$
w_{\alpha}=P_{S}\left[(1-\alpha \gamma) I-\gamma G^{*} G\right] w_{\alpha} .
$$

Theorem 2.7 Let $w_{\alpha}$ be given as (2.4). Then $w_{\alpha}$ converges strongly as $\alpha \rightarrow 0$ to the minimum-norm solution $\tilde{w}$ of SEP (1.1).

Proof Let $\check{w}$ be a point in $\Gamma$. Since $\alpha \in\left(0, \frac{2-\gamma\left\|G^{*} G\right\|}{2 \gamma}\right), I-\frac{\gamma}{(1-\alpha \gamma)} G^{*} G$ is nonexpansive. It follows that

$$
\begin{aligned}
\left\|w_{\alpha}-\check{w}\right\| & =\left\|P_{S}\left[(1-\alpha \gamma) I-\gamma G^{*} G\right] w_{\alpha}-P_{S}\left[\check{w}-\gamma G^{*} G \check{w}\right]\right\| \\
& \leq\left\|\left[(1-\alpha \gamma) I-\gamma G^{*} G\right] w_{\alpha}-\left[\check{w}-\gamma G^{*} G \check{w}\right]\right\| \\
& =\left\|(1-\alpha \gamma)\left[w_{\alpha}-\frac{\gamma}{1-\alpha \gamma} G^{*} G w_{\alpha}\right]-(1-\alpha \gamma)\left[\check{w}-\frac{\gamma}{1-\alpha \gamma} G^{*} G \check{w}\right]-\alpha \gamma \check{w}\right\| \\
& \leq(1-\alpha \gamma)\left\|\left(w_{\alpha}-\frac{\gamma}{1-\alpha \gamma} G^{*} G w_{\alpha}\right)-\left(\check{w}-\frac{\gamma}{1-\alpha \gamma} G^{*} G \check{w}\right)\right\|+\alpha \gamma\|\check{w}\| \\
& \leq(1-\alpha \gamma)\left\|w_{\alpha}-\check{w}\right\|+\alpha \gamma\|\check{w}\| .
\end{aligned}
$$

Hence,

$$
\left\|w_{\alpha}-\check{w}\right\| \leq\|\check{w}\| .
$$

Then $\left\{w_{\alpha}\right\}$ is bounded.

From (2.4), we have

$$
\left\|w_{\alpha}-P_{S}\left[I-\gamma G^{*} G\right] w_{\alpha}\right\| \leq \alpha\left\|\gamma w_{\alpha}\right\| \rightarrow 0 .
$$

Next we show that $\left\{w_{\alpha}\right\}$ is relatively norm compact as $\alpha \rightarrow 0^{+}$. In fact, assume that $\left\{\beta_{n}\right\} \subseteq$ $\left(0, \frac{2-\gamma\left\|G^{*} G\right\|}{2 \gamma}\right)$ is such that $\alpha_{n} \rightarrow 0^{+}$as $n \rightarrow \infty$. Put $w_{n}:=w_{\alpha_{n}}$, we have the following:

$$
\left\|w_{n}-P_{S}\left[I-\gamma G^{*} G\right] w_{n}\right\| \leq \alpha_{n}\left\|\gamma w_{n}\right\| \rightarrow 0 .
$$


By the property of the projection, we deduce that

$$
\begin{aligned}
\left\|w_{\alpha}-\check{w}\right\|^{2}= & \left\|P_{S}\left[(1-\alpha \gamma) I-\gamma G^{*} G\right] w_{\alpha}-P_{S}\left[\check{w}-\gamma G^{*} G \check{w}\right]\right\|^{2} \\
\leq & \left\langle\left[(1-\alpha \gamma) I-\gamma G^{*} G\right] w_{\alpha}-\left[\check{w}-\gamma G^{*} G \check{w}\right], w_{\alpha}-\check{w}\right\rangle \\
= & \left\langle(1-\alpha \gamma)\left[w_{\alpha}-\frac{\gamma}{1-\alpha \gamma} G^{*} G w_{\alpha}\right]-(1-\alpha \gamma)\left[\check{w}-\frac{\gamma}{1-\alpha \gamma} G^{*} G \check{w}\right], w_{\alpha}-\check{w}\right\rangle \\
& -\alpha \gamma\left\langle\check{w}, w_{\alpha}-\check{w}\right\rangle \\
\leq & (1-\alpha \gamma)\left\|w_{\alpha}-\check{w}\right\|^{2}-\alpha \gamma\left\langle\check{w}, w_{\alpha}-\check{w}\right\rangle .
\end{aligned}
$$

Therefore,

$$
\left\|w_{\alpha}-\check{w}\right\|^{2} \leq\left\langle-\check{w}, w_{\alpha}-\check{w}\right\rangle .
$$

In particular,

$$
\left\|w_{n}-\check{w}\right\|^{2} \leq\left\langle-\check{w}, w_{n}-\check{w}\right\rangle, \quad \forall \check{w} \in \Gamma .
$$

Since $\left\{w_{n}\right\}$ is bounded, there exists a subsequence of $\left\{w_{n}\right\}$ which converges weakly to a point $\tilde{w}$. Without loss of generality, we may assume that $\left\{w_{n}\right\}$ converges weakly to $\tilde{w}$. Notice that

$$
\left\|w_{n}-P_{S}\left[I-\gamma G^{*} G\right] w_{n}\right\| \leq \alpha_{n}\left\|\gamma w_{n}\right\| \rightarrow 0,
$$

and by Lemma 1.1 we can get that $\tilde{w} \in \operatorname{Fix}\left(P_{S}\left[I-\gamma G^{*} G\right]\right)=\Gamma$.

By

$$
\left\|w_{n}-\check{w}\right\|^{2} \leq\left\langle-\check{w}, w_{n}-\check{w}\right\rangle, \quad \forall \check{w} \in \Gamma,
$$

we have

$$
\left\|w_{n}-\tilde{w}\right\|^{2} \leq\left\langle-\tilde{w}, w_{n}-\tilde{w}\right\rangle
$$

Consequently, $\left\{w_{n}\right\}$ converges weakly to $\tilde{w}$ actually implies that $\left\{w_{n}\right\}$ converges strongly to $\tilde{w}$. That is to say, $\left\{w_{\alpha}\right\}$ is relatively norm compact as $\alpha \rightarrow 0^{+}$.

On the other hand, by

$$
\left\|w_{n}-\check{w}\right\|^{2} \leq\left\langle-\check{w}, w_{n}-\check{w}\right\rangle, \quad \forall \check{w} \in \Gamma,
$$

let $n \rightarrow \infty$, we have

$$
\|\tilde{w}-\check{w}\|^{2} \leq\langle-\check{w}, \tilde{w}-\check{w}\rangle, \quad \forall \check{w} \in \Gamma .
$$

This implies that

$$
\langle-\check{w}, \check{w}-\tilde{w}\rangle \leq 0, \quad \forall \check{w} \in \Gamma,
$$


which is equivalent to

$$
\langle-\tilde{w}, \check{w}-\tilde{w}\rangle \leq 0, \quad \forall \check{w} \in \Gamma .
$$

It follows that $\tilde{w} \in P_{S}(0)$. Therefore, each cluster point of $w_{\alpha}$ equals $\tilde{w}$. So $w_{\alpha} \rightarrow \tilde{w}(\alpha \rightarrow 0)$ the minimum-norm solution of SEP.

\section{Modification of Moudafi's ACQA and RACQA algorithms}

In this section, we introduce the following algorithm which is viewed as a modification of Moudafi's ACQA and RACQA algorithms. The purpose for such a modification lies in the hope of strong convergence.

Algorithm 3.1 For an arbitrary point $w_{0}=\left(x_{0}, y_{0}\right) \in H=H_{1} \times H_{2}$, the sequence $\left\{w_{n}\right\}=$ $\left\{\left(x_{n}, y_{n}\right)\right\}$ is generated by the iterative algorithm

$$
w_{n+1}=P_{S}\left\{\left(1-\alpha_{n}\right)\left[I-\gamma G^{*} G\right] w_{n}\right\},
$$

i.e.,

$$
\begin{cases}x_{n+1}=P_{C}\left\{\left(1-\alpha_{n}\right)\left[x_{n}-\gamma A^{*}\left(A x_{n}-B y_{n}\right)\right]\right\}, & n \geq 0 ; \\ y_{n+1}=P_{Q}\left\{\left(1-\alpha_{n}\right)\left[y_{n}+\gamma B^{*}\left(A x_{n}-B y_{n}\right)\right]\right\}, & n \geq 0,\end{cases}
$$

where $\alpha_{n}>0$ is a sequence in $(0,1)$ such that

(i) $\lim _{n} \alpha_{n}=0$;

(ii) $\sum_{n=0}^{\infty} \alpha_{n}=\infty$;

(iii) $\sum_{n=0}^{\infty}\left|\alpha_{n+1}-\alpha_{n}\right|<\infty$ or $\lim _{n}\left|\alpha_{n+1}-\alpha_{n}\right| / \alpha_{n}=0$.

Now, we prove the strong convergence of the iterative algorithm.

Theorem 3.2 The sequence $\left\{w_{n}\right\}$ generated by algorithm (3.1) converges strongly to the minimum-norm solution $\tilde{w}$ of SEP (1.1).

Proof Let $R_{n}$ and $R$ be defined by

$$
\begin{aligned}
& R_{n} w:=P_{S}\left\{\left(1-\alpha_{n}\right)\left[I-\gamma G^{*} G\right]\right\} w=P_{S}\left[\left(1-\alpha_{n}\right) T w\right], \\
& R w:=P_{S}\left(I-\gamma G^{*} G\right) w=P_{S}(T w),
\end{aligned}
$$

where $T=I-\gamma G^{*} G$. By Lemma 2.5 it is easy to see that $R_{n}$ is a contraction with contractive constant $1-\alpha_{n}$; and algorithm (3.1) can be written as $w_{n+1}=R_{n} w_{n}$.

For any $\hat{w} \in \Gamma$, we have

$$
\begin{aligned}
\left\|R_{n} \hat{w}-\hat{w}\right\| & =\left\|P_{S}\left[\left(1-\alpha_{n}\right) T \hat{w}\right]-\hat{w}\right\| \\
& =\left\|P_{S}\left[\left(1-\alpha_{n}\right) T \hat{w}\right]-P_{S}(T \hat{w})\right\| \\
& \leq\left\|\left(1-\alpha_{n}\right) T \hat{w}-T \hat{w}\right\| \\
& =\alpha_{n}\|T \hat{w}\| \leq \alpha_{n}\|\hat{w}\| .
\end{aligned}
$$


Hence,

$$
\begin{aligned}
\left\|w_{n+1}-\hat{w}\right\| & =\left\|R_{n} w_{n}-\hat{w}\right\| \leq\left\|R_{n} w_{n}-R_{n} \hat{w}\right\|+\left\|R_{n} \hat{w}-\hat{w}\right\| \\
& \leq\left\|P_{S}\left[\left(1-\alpha_{n}\right) T \hat{w}\right]-P_{S}(T \hat{w})\right\| \\
& \leq\left(1-\alpha_{n}\right)\left\|w_{n}-\hat{w}\right\|+\alpha_{n}\|\hat{w}\| \\
& \leq \max \left\{\left\|w_{n}-\hat{w}\right\|,\|\hat{w}\|\right\} .
\end{aligned}
$$

It follows that $\left\|w_{n}-\hat{w}\right\| \leq \max \left\{\left\|w_{0}-\hat{w}\right\|,\|\hat{w}\|\right\}$. So $\left\{w_{n}\right\}$ is bounded.

Next we prove that $\lim _{n}\left\|w_{n+1}-w_{n}\right\|=0$.

Indeed,

$$
\begin{aligned}
\left\|w_{n+1}-w_{n}\right\| & =\left\|R_{n} w_{n}-R_{n-1} w_{n-1}\right\| \\
& \leq\left\|R_{n} w_{n}-R_{n} w_{n-1}\right\|+\left\|R_{n} w_{n-1}-R_{n-1} w_{n-1}\right\| \\
& \leq\left(1-\alpha_{n}\right)\left\|w_{n}-w_{n-1}\right\|+\left\|R_{n} w_{n-1}-R_{n-1} w_{n-1}\right\| .
\end{aligned}
$$

Notice that

$$
\begin{aligned}
\left\|R_{n} w_{n-1}-R_{n-1} w_{n-1}\right\| & =\left\|P_{S}\left[\left(1-\alpha_{n}\right) T w_{n-1}\right]-P_{S}\left[\left(1-\alpha_{n-1}\right) T w_{n-1}\right]\right\| \\
& \leq\left\|\left(1-\alpha_{n}\right) T w_{n-1}-\left(1-\alpha_{n-1}\right) T w_{n-1}\right\| \\
& =\left|\alpha_{n}-\alpha_{n-1}\right|\left\|T w_{n-1}\right\| \\
& \leq\left|\alpha_{n}-\alpha_{n-1}\right|\left\|w_{n-1}\right\| .
\end{aligned}
$$

Hence,

$$
\left\|w_{n+1}-w_{n}\right\| \leq\left(1-\alpha_{n}\right)\left\|w_{n}-w_{n-1}\right\|+\left|\alpha_{n}-\alpha_{n-1}\right|\left\|w_{n-1}\right\|
$$

By virtue of assumptions (1)-(3) and Lemma 1.2, we have

$$
\lim _{n}\left\|w_{n+1}-w_{n}\right\|=0 .
$$

Therefore,

$$
\begin{aligned}
\left\|w_{n}-R w_{n}\right\| & \leq\left\|w_{n+1}-w_{n}\right\|+\left\|R_{n} w_{n}-R w_{n}\right\| \\
& \leq\left\|w_{n+1}-w_{n}\right\|+\left\|\left(1-\alpha_{n}\right) T w_{n}-T w_{n}\right\| \\
& \leq\left\|w_{n+1}-w_{n}\right\|+\alpha_{n}\left\|w_{n}\right\| \rightarrow 0
\end{aligned}
$$

The demiclosedness principle ensures that each weak limit point of $\left\{w_{n}\right\}$ is a fixed point of the nonexpansive mapping $R=P_{S} T$, that is, a point of the solution set $\Gamma$ of SEP (1.1). At last, we will prove that $\lim _{n}\left\|w_{n+1}-\tilde{w}\right\|=0$. 
Choose $0<\beta<1$ such that $\gamma /(1-\beta)<2 / \rho\left(G^{*} G\right)$, then $T=I-\gamma G^{*} G=\beta I+(1-\beta) V$, where $V=I-\gamma /(1-\beta) G^{*} G$ is a nonexpansive mapping. Taking $z \in \Gamma$, we deduce that

$$
\begin{aligned}
\left\|w_{n+1}-z\right\|^{2} & =\left\|P_{S}\left[\left(1-\alpha_{n}\right) T w_{n}\right]-z\right\|^{2} \\
& \leq\left\|\left(1-\alpha_{n}\right) T w_{n}-z\right\|^{2} \\
& \leq\left(1-\alpha_{n}\right)\left\|T w_{n}-z\right\|^{2}+\alpha_{n}\|z\|^{2} \\
& \leq\left\|\beta\left(w_{n}-z\right)+(1-\beta)\left(V w_{n}-z\right)\right\|^{2}+\alpha_{n}\|z\|^{2} \\
& \leq \beta\left\|\left(w_{n}-z\right)\right\|^{2}+(1-\beta)\left\|\left(V w_{n}-z\right)\right\|^{2}-\beta(1-\beta)\left\|w_{n}-V w_{n}\right\|^{2}+\alpha_{n}\|z\|^{2} \\
& \leq\left\|\left(w_{n}-z\right)\right\|^{2}-\beta(1-\beta)\left\|w_{n}-V w_{n}\right\|^{2}+\alpha_{n}\|z\|^{2} .
\end{aligned}
$$

Then

$$
\begin{aligned}
\beta(1-\beta)\left\|w_{n}-V w_{n}\right\| & \leq\left\|w_{n}-z\right\|^{2}-\left\|w_{n+1}-z\right\|^{2}+\alpha_{n}\|z\|^{2} \\
& \leq\left(\left\|w_{n}-z\right\|+\left\|w_{n+1}-z\right\|\right)\left(\left\|w_{n}-z\right\|-\left\|w_{n+1}-z\right\|\right) \alpha_{n}\|z\|^{2} \\
& \leq\left(\left\|w_{n}-z\right\|+\left\|w_{n+1}-z\right\|\right)\left(\left\|w_{n}-w_{n+1}\right\|\right) \alpha_{n}\|z\|^{2} \rightarrow 0 .
\end{aligned}
$$

Note that $T=I-\gamma G^{*} G=\beta I+(1-\beta) V$, it follows that $\lim _{n}\left\|T w_{n}-w_{n}\right\|=0$.

Take a subsequence $\left\{w_{n_{k}}\right\}$ of $\left\{w_{n}\right\}$ such that $\lim \sup _{n}\left\langle w_{n}-\tilde{w},-\tilde{w}\right\rangle=\lim _{k}\left\langle w_{n_{k}}-\tilde{w},-\tilde{w}\right\rangle$.

By virtue of the boundedness of $w_{n}$, we may further assume, with no loss of generality, that $w_{n_{k}}$ converges weakly to a point $\check{w}$. Since $\left\|R w_{n}-w_{n}\right\| \rightarrow 0$, using the demiclosedness principle, we know that $\check{w} \in \operatorname{Fix}(R)=\operatorname{Fix}\left(P_{S} T\right)=\Gamma$. Noticing that $\tilde{w}$ is the projection of the origin onto $\Gamma$, we get that

$$
\limsup _{n}\left\langle w_{n}-\tilde{w},-\tilde{w}\right\rangle=\lim _{k}\left\langle w_{n_{k}}-\tilde{w},-\tilde{w}\right\rangle=\langle\check{w}-\tilde{w},-\tilde{w}\rangle \leq 0
$$

Finally, we compute

$$
\begin{aligned}
\left\|w_{n+1}-\tilde{w}\right\|^{2} & =\left\|P_{S}\left[\left(1-\alpha_{n}\right) T w_{n}\right]-\tilde{w}\right\|^{2} \\
& =\left\|P_{S}\left[\left(1-\alpha_{n}\right) T w_{n}\right]-P_{S} T \tilde{w}\right\|^{2} \\
& \leq\left\|\left(1-\alpha_{n}\right) T w_{n}-T \tilde{w}\right\|^{2} \\
& =\left\|\left(1-\alpha_{n}\right) T w_{n}-\tilde{w}\right\|^{2} \\
& =\left\|\left(1-\alpha_{n}\right)\left(T w_{n}-\tilde{w}\right)+\alpha_{n}(-\tilde{w})\right\|^{2} \\
& =\left(1-\alpha_{n}\right)^{2}\left\|\left(T w_{n}-\tilde{w}\right)\right\|^{2}+\alpha_{n}^{2}\|\tilde{w}\|^{2}+2 \alpha_{n}\left(1-\alpha_{n}\right)\left\langle T w_{n}-\tilde{w},-\tilde{w}\right\rangle \\
& \leq\left(1-\alpha_{n}\right)\left\|\left(T w_{n}-\tilde{w}\right)\right\|^{2}+\alpha_{n}\left[\alpha_{n}\|\tilde{w}\|^{2}+2\left(1-\alpha_{n}\right)\left\langle T w_{n}-\tilde{w},-\tilde{w}\right\rangle\right] .
\end{aligned}
$$

Since $\lim \sup _{n}\left\langle w_{n}-\tilde{w},-\tilde{w}\right\rangle \leq 0,\left\|w_{n}-T w_{n}\right\| \rightarrow 0$, we know that $\lim \sup _{n}\left(\alpha_{n}\|\tilde{w}\|^{2}+2(1-\right.$ $\left.\left.\alpha_{n}\right)\left\langle T w_{n}-\tilde{w},-\tilde{w}\right\rangle\right) \leq 0$. By Lemma 1.2, we conclude that $\lim _{n}\left\|w_{n+1}-\tilde{w}\right\|=0$. This completes the proof.

Remark 3.3 When $B=I$, the iteration algorithm (3.1) becomes

$$
x_{n+1}=P_{C}\left\{\left(1-\alpha_{n}\right)\left[x_{n}-\gamma A^{*}\left(A x_{n}-y_{n}\right)\right]\right\} ;
$$




$$
y_{n+1}=P_{Q}\left\{\left(1-\alpha_{n}\right)\left[y_{n}+\gamma\left(A x_{n}-y_{n}\right)\right]\right\}
$$

By Theorem 3.2, we can get the following result.

Corollary 3.4 For an arbitrary point $w_{0}=\left(x_{0}, y_{0}\right) \in H=H_{1} \times H_{2}$, the sequence $\left\{w_{n}\right\}=$ $\left\{\left(x_{n}, y_{n}\right)\right\}$ is generated by the iterative algorithm

$$
\left\{\begin{array}{l}
x_{n+1}=P_{C}\left\{\left(1-\alpha_{n}\right)\left[x_{n}-\gamma A^{*}\left(A x_{n}-y_{n}\right)\right]\right\}, \quad n \geq 0 \\
y_{n+1}=P_{Q}\left\{\left(1-\alpha_{n}\right)\left[y_{n}+\gamma\left(A x_{n}-y_{n}\right)\right]\right\}, \quad n \geq 0
\end{array}\right.
$$

where $\alpha_{n}>0$ is a sequence in $(0,1)$ such that

(i) $\lim _{n} \alpha_{n}=0$;

(ii) $\sum_{n=0}^{\infty} \alpha_{n}=\infty$;

(iii) $\sum_{n=0}^{\infty}\left|\alpha_{n+1}-\alpha_{n}\right|<\infty$ or $\lim _{n}\left|\alpha_{n+1}-\alpha_{n}\right| / \alpha_{n}=0$.

Then $x_{n}$ converges strongly to the minimum-norm solution of SFP.

\section{KM-CQ-like iterative algorithm for SEP}

In this section, we establish a KM-CQ-like algorithm converging strongly to a solution of SEP.

Algorithm 4.1 For an arbitrary initial point $w_{0}=\left(x_{0}, y_{0}\right)$, the sequence $\left\{w_{n}=\left(x_{n}, y_{n}\right)\right\}$ is generated by the iteration

$$
w_{n+1}=\left(1-\beta_{n}\right) w_{n}+\beta_{n} P_{S}\left[\left(1-\alpha_{n}\right)\left(I-\gamma G^{*} G\right)\right] w_{n}
$$

i.e.,

$$
\begin{cases}x_{n+1}=\left(1-\beta_{n}\right) x_{n}+\beta_{n} P_{C}\left\{\left(1-\alpha_{n}\right)\left[x_{n}-\gamma A^{*}\left(A x_{n}-B y_{n}\right)\right]\right\}, & n \geq 0 ; \\ y_{n+1}=\left(1-\beta_{n}\right) y_{n}+\beta_{n} P_{Q}\left\{\left(1-\alpha_{n}\right)\left[y_{n}+\gamma B^{*}\left(A x_{n}-B y_{n}\right)\right]\right\}, & n \geq 0,\end{cases}
$$

where $\alpha_{n}>0$ is a sequence in $(0,1)$ such that

(i) $\lim _{n \rightarrow \infty} \alpha_{n}=0, \sum_{n=0}^{\infty} \alpha_{n}=\infty$;

(ii) $\lim _{n \rightarrow \infty}\left|\alpha_{n+1}-\alpha_{n}\right|=0$;

(iii) $0<\liminf _{n \rightarrow \infty} \beta_{n} \leq \limsup _{n \rightarrow \infty} \beta_{n}<1$.

Lemma 4.2 If $z \in \operatorname{Fix}(T)=\operatorname{Fix}\left(I-\gamma G^{*} G\right)$, then for any $w$ we have $\|T w-z\|^{2} \leq\|w-z\|^{2}-$ $\beta(1-\beta)\|V w-w\|^{2}$, where $\beta$ and $V$ are the same as in Lemma 2.5(1).

Proof According to Lemma 2.5(1), we know that $T=\beta I+(1-\beta) V$, where $0<\beta<1$ and $V$ is nonexpansive. It is easy to check that $z \in \operatorname{Fix}(T)=\operatorname{Fix}(V)$, and

$$
\begin{aligned}
\|T w-z\|^{2} & =\|\beta w+(1-\beta) V w-z\|^{2} \\
& \leq \beta\|w-z\|^{2}+(1-\beta)\|V w-z\|^{2}-\beta(1-\beta)\|V w-w\|^{2} \\
& \leq \beta\|w-z\|^{2}+(1-\beta)\|w-z\|^{2}-\beta(1-\beta)\|V w-w\|^{2} \\
& =\|w-z\|^{2}-\beta(1-\beta)\|V w-w\|^{2} .
\end{aligned}
$$


Theorem 4.3 The sequence $\left\{w_{n}\right\}$ generated by algorithm (4.1) converges strongly to a solution of SEP (1.1).

Proof For any solution of SEP $\hat{w}$, according to Lemma 2.5, $\hat{w} \in \operatorname{Fix}\left(P_{S} T\right)=\operatorname{Fix}\left(P_{S}\right) \cap \operatorname{Fix}(T)$, where $T=I-\gamma G^{*} G$, and

$$
\begin{aligned}
\left\|w_{n+1}-\hat{w}\right\|= & \left\|\left(1-\beta_{n}\right) w_{n}+\beta_{n} P_{S}\left[\left(1-\alpha_{n}\right) T\right] w_{n}-\hat{w}\right\| \\
= & \left\|\left(1-\beta_{n}\right)\left(w_{n}-\hat{w}\right)+\beta_{n}\left(P_{S}\left[\left(1-\alpha_{n}\right) T\right] w_{n}-\hat{w}\right)\right\| \\
\leq & \left(1-\beta_{n}\right)\left\|w_{n}-\hat{w}\right\|+\beta_{n}\left\|P_{S}\left[\left(1-\alpha_{n}\right) T\right] w_{n}-\hat{w}\right\| \\
\leq & \left(1-\beta_{n}\right)\left\|w_{n}-\hat{w}\right\| \\
& +\beta_{n}\left\|P_{S}\left[\left(1-\alpha_{n}\right) T\right] w_{n}-P_{S}\left[\left(1-\alpha_{n}\right) T\right] \hat{w}\right\| \\
& +\beta_{n}\left\|P_{S}\left[\left(1-\alpha_{n}\right) T\right] \hat{w}-\hat{w}\right\| \\
\leq & \left(1-\beta_{n}\right)\left\|w_{n}-\hat{w}\right\|+\beta_{n}\left(1-\alpha_{n}\right)\left\|w_{n}-\hat{w}\right\|+\beta_{n} \alpha_{n}\|\hat{w}\| \\
= & \left(1-\beta_{n} \alpha_{n}\right)\left\|w_{n}-\hat{w}\right\|+\beta_{n} \alpha_{n}\|\hat{w}\| \\
\leq & \max \left\{\left\|w_{n}-\hat{w}\right\|,\|\hat{w}\|\right\} .
\end{aligned}
$$

By induction,

$$
\left\|w_{n}-\hat{w}\right\| \leq \max \left\{\left\|w_{0}-\hat{w}\right\|,\|\hat{w}\|\right\}
$$

Hence, $\left\{w_{n}\right\}$ is bounded and so is $\left\{T w_{n}\right\}$. Moreover,

$$
\begin{aligned}
\left\|P_{S}\left[\left(1-\alpha_{n}\right) T\right] w_{n}-\hat{w}\right\| & \leq\left\|\left(1-\alpha_{n}\right) T w_{n}-\hat{w}\right\| \\
& =\left\|\left(1-\alpha_{n}\right)\left[T w_{n}-\hat{w}\right]-\alpha_{n} \hat{w}\right\| \\
& \leq\left(1-\alpha_{n}\right)\left\|w_{n}-\hat{w}\right\|+\alpha_{n}\|\hat{w}\| \\
& \leq \max \left\{\left\|w_{n}-\hat{w}\right\|,\|\hat{w}\|\right\} .
\end{aligned}
$$

Since $\left\{w_{n}\right\}$ is bounded, we have that $\left\{T w_{n}\right\},\left(1-\alpha_{n}\right) T w_{n}$ and $\left\{P_{S}\left[\left(1-\alpha_{n}\right) T\right] w_{n}\right\}$ are also bounded.

Let $z_{n}=P_{S}\left[\left(1-\alpha_{n}\right) T\right] w_{n}$, and $M>0$ such that $M=\sup _{n \geq 1}\left\{T w_{n}\right\}$. We observe that

$$
\begin{aligned}
\left\|P_{S}\left[\left(1-\alpha_{n+1}\right) T\right] w_{n}-P_{S}\left[\left(1-\alpha_{n}\right) T\right] w_{n}\right\| & \leq\left\|\left(1-\alpha_{n+1}\right) T w_{n}-\left(1-\alpha_{n}\right) T w_{n}\right\| \\
& =\left\|\left(\alpha_{n}-\alpha_{n+1}\right) T w_{n}\right\| \\
& \leq M\left|\alpha_{n}-\alpha_{n+1}\right| .
\end{aligned}
$$

Hence,

$$
\begin{aligned}
\left\|z_{n+1}-z_{n}\right\|= & \left\|P_{S}\left[\left(1-\alpha_{n+1}\right) T\right] w_{n+1}-P_{S}\left[\left(1-\alpha_{n}\right) T\right] w_{n}\right\| \\
\leq & \left\|P_{S}\left[\left(1-\alpha_{n+1}\right) T\right] w_{n+1}-P_{S}\left[\left(1-\alpha_{n+1}\right) T\right] w_{n}\right\| \\
& +\left\|P_{S}\left[\left(1-\alpha_{n+1}\right) T\right] w_{n}-P_{S}\left[\left(1-\alpha_{n}\right) T\right] w_{n}\right\|
\end{aligned}
$$




$$
\begin{aligned}
& \leq\left(1-\alpha_{n+1}\right)\left\|w_{n+1}-w_{n}\right\|+\left\|P_{S}\left[\left(1-\alpha_{n+1}\right) T\right] w_{n}-P_{S}\left[\left(1-\alpha_{n}\right) T\right] w_{n}\right\| \\
& \leq\left(1-\alpha_{n+1}\right)\left\|w_{n+1}-w_{n}\right\|+M\left|\alpha_{n}-\alpha_{n+1}\right| .
\end{aligned}
$$

Since $0<\alpha_{n}<1$ and $\lim _{n \rightarrow \infty}\left|\alpha_{n+1}-\alpha_{n}\right|=0$, we obtain that

$$
\left\|z_{n+1}-z_{n}\right\|-\left\|w_{n+1}-w_{n}\right\| \leq M\left|\alpha_{n}-\alpha_{n+1}\right|
$$

and

$$
\limsup _{n \rightarrow \infty}\left\|z_{n+1}-z_{n}\right\|-\left\|w_{n+1}-w_{n}\right\| \leq 0 \text {. }
$$

Using Lemma 1.3, we get that

$$
\lim _{n \rightarrow \infty}\left\|P_{S}\left[\left(1-\alpha_{n}\right) T\right] w_{n}-w_{n}\right\|=\lim _{n \rightarrow \infty}\left\|z_{n}-w_{n}\right\|=0 .
$$

Therefore,

$$
\begin{aligned}
\left\|w_{n+1}-w_{n}\right\| & =\left\|\left(1-\beta_{n}\right) w_{n}+\beta_{n} P_{S}\left[\left(1-\alpha_{n}\right) T\right] w_{n}-w_{n}\right\| \\
& =\beta_{n}\left\|P_{S}\left[\left(1-\alpha_{n}\right) T\right] w_{n}-w_{n}\right\| \rightarrow 0 .
\end{aligned}
$$

Let $R_{n}$ and $R$ be defined by

$$
\begin{aligned}
& R_{n} w:=P_{S}\left\{\left(1-\alpha_{n}\right)\left[I-\gamma G^{*} G\right]\right\} w=P_{S}\left[\left(1-\alpha_{n}\right) T w\right], \\
& R w:=P_{S}\left(I-\gamma G^{*} G\right) w=P_{S}(T w) .
\end{aligned}
$$

We find

$$
\begin{aligned}
\left\|w_{n}-R w_{n}\right\| & \leq\left\|w_{n}-w_{n+1}\right\|+\left\|w_{n+1}-R w_{n}\right\| \\
& =\left\|w_{n}-w_{n+1}\right\|+\left\|\left(1-\beta_{n}\right) w_{n}+\beta_{n} R_{n} w_{n}-R w_{n}\right\| \\
& \leq\left\|w_{n}-w_{n+1}\right\|+\left(1-\beta_{n}\right)\left\|w_{n}-R w_{n}\right\|+\beta_{n}\left\|R_{n} w_{n}-R w_{n}\right\| .
\end{aligned}
$$

So, we have

$$
\begin{aligned}
\left\|w_{n}-R w_{n}\right\| & \leq\left\|w_{n}-w_{n+1}\right\| / \beta_{n}+\left\|R_{n} w_{n}-R w_{n}\right\| \\
& =\left\|w_{n}-w_{n+1}\right\| / \beta_{n}+\left\|P_{S}\left[\left(1-\alpha_{n}\right) T\right] w_{n}-P_{S} T w_{n}\right\| \\
& \leq\left\|w_{n}-w_{n+1}\right\| / \beta_{n}+\left\|\left(1-\alpha_{n}\right) T w_{n}-T w_{n}\right\| \\
& \leq\left\|w_{n}-w_{n+1}\right\| / \beta_{n}+M \alpha_{n} .
\end{aligned}
$$

By assumption, we have

$$
\lim _{n \rightarrow \infty}\left\|w_{n}-R w_{n}\right\|=0 .
$$

On the other hand, $\left\{w_{n}\right\}$ is bounded, there exists a subsequence of $\left\{w_{n}\right\}$ which converges weakly to a point $\check{w}$. Without loss of generality, we may assume that $\left\{w_{n}\right\}$ converges weakly 
to $\check{w}$. Since $\left\|R w_{n}-w_{n}\right\| \rightarrow 0$, using the demiclosedness principle we know that $\check{w} \in \operatorname{Fix}(R)=$ $\operatorname{Fix}\left(P_{S} T\right)=\operatorname{Fix}\left(P_{S}\right) \cap \operatorname{Fix}(T)=\Gamma$.

At last, we will prove that $\lim _{n}\left\|w_{n+1}-\check{w}\right\|=0$. To do this, we calculate

$$
\begin{aligned}
\left\|w_{n+1}-\check{w}\right\|^{2}= & \left\|\left(1-\beta_{n}\right) w_{n}+\beta_{n} P_{S}\left[\left(1-\alpha_{n}\right) T\right] w_{n}-P_{S} T \check{w}\right\|^{2} \\
\leq & \left(1-\beta_{n}\right)\left\|w_{n}-\check{w}\right\|^{2}+\beta_{n}\left\|P_{S}\left[\left(1-\alpha_{n}\right) T\right] w_{n}-P_{S} T \check{w}\right\|^{2} \\
\leq & \left(1-\beta_{n}\right)\left\|w_{n}-\check{w}\right\|^{2}+\beta_{n}\left\|\left(1-\alpha_{n}\right) T w_{n}-\check{w}\right\|^{2} \\
= & \left(1-\beta_{n}\right)\left\|w_{n}-\check{w}\right\|^{2}+\beta_{n}\left\|\left(1-\alpha_{n}\right)\left(T w_{n}-\check{w}\right)+\alpha_{n} \check{w}\right\|^{2} \\
= & \left(1-\beta_{n}\right)\left\|w_{n}-\check{w}\right\|^{2}+\beta_{n}\left[\left(1-\alpha_{n}\right)^{2}\left\|T w_{n}-\check{w}\right\|^{2}+\alpha_{n}^{2}\|\check{w}\|^{2}\right. \\
& \left.+2 \alpha_{n}\left(1-\alpha_{n}\right)\left\langle T w_{n}-\check{w},-\check{w}\right\rangle\right] \\
\leq & \left(1-\beta_{n}\right)\left\|w_{n}-\check{w}\right\|^{2}+\beta_{n}\left[\left(1-\alpha_{n}\right)\left\|w_{n}-\check{w}\right\|^{2}+\alpha_{n}^{2}\|\check{w}\|^{2}\right. \\
& \left.+2 \alpha_{n}\left(1-\alpha_{n}\right)\left\langle T w_{n}-\check{w},-\check{w}\right\rangle\right] \\
= & \left(1-\alpha_{n} \beta_{n}\right)\left\|w_{n}-\check{w}\right\|^{2}+\alpha_{n} \beta_{n}\left[2\left(1-\alpha_{n}\right)\left\langle T w_{n}-\check{w},-\check{w}\right\rangle+\alpha_{n}\|\check{w}\|^{2}\right] .
\end{aligned}
$$

By Lemma 1.2, we only need to prove that

$$
\limsup _{n \rightarrow \infty}\left\langle T w_{n}-\check{w},-\check{w}\right\rangle \leq 0 .
$$

By Lemma 2.5, $T$ is averaged, that is, $T=\beta I+(1-\beta) V$, where $0<\beta<1$ and $V$ is nonexpansive. Then, for $z \in \operatorname{Fix}\left(P_{S} T\right)$, we have

$$
\begin{aligned}
\left\|w_{n+1}-z\right\|^{2} & =\left\|\left(1-\beta_{n}\right) w_{n}+\beta_{n} P_{S}\left[\left(1-\alpha_{n}\right) T\right] w_{n}-z\right\|^{2} \\
& \leq\left(1-\beta_{n}\right)\left\|w_{n}-z\right\|^{2}+\beta_{n}\left\|\left(1-\alpha_{n}\right) T w_{n}-z\right\|^{2} \\
& =\left(1-\beta_{n}\right)\left\|w_{n}-z\right\|^{2}+\beta_{n}\left\|\left(1-\alpha_{n}\right)\left(T w_{n}-z\right)-\alpha_{n} z\right\|^{2} \\
& \leq\left(1-\beta_{n}\right)\left\|w_{n}-z\right\|^{2}+\beta_{n}\left[\left(1-\alpha_{n}\right)\left\|T w_{n}-z\right\|^{2}+\alpha_{n}\|z\|^{2}\right] \\
& \leq\left(1-\beta_{n}\right)\left\|w_{n}-z\right\|^{2}+\beta_{n}\left[\left\|T w_{n}-z\right\|^{2}+\alpha_{n}\|z\|^{2}\right] .
\end{aligned}
$$

By Lemma 4.2, we can get

$$
\begin{aligned}
\left\|w_{n+1}-z\right\|^{2} \leq & \left(1-\beta_{n}\right)\left\|w_{n}-z\right\|^{2} \\
& +\beta_{n}\left[\left\|w_{n}-z\right\|^{2}-\beta(1-\beta)\left\|V w_{n}-w_{n}\right\|^{2}+\alpha_{n}\|z\|^{2}\right] \\
\leq & \left\|w_{n}-z\right\|^{2}-\beta_{n} \beta(1-\beta)\left\|V w_{n}-w_{n}\right\|^{2}+\beta_{n} \alpha_{n}\|z\|^{2} .
\end{aligned}
$$

Let $K>0$ such that $\left\|w_{n}-z\right\| \leq K$ for all $n$, then we have

$$
\begin{aligned}
\beta_{n} \beta(1-\beta)\left\|V w_{n}-w_{n}\right\|^{2} & \leq\left\|w_{n}-z\right\|^{2}-\left\|w_{n+1}-z\right\|^{2}+\beta_{n} \alpha_{n}\|z\|^{2} \\
& \leq 2 N\left|\left\|w_{n}-z\right\|-\left\|w_{n+1}-z\right\|\right|+\beta_{n} \alpha_{n}\|z\|^{2} \\
& \leq 2 N\left\|w_{n}-w_{n+1}\right\|+\beta_{n} \alpha_{n}\|z\|^{2} .
\end{aligned}
$$


Hence,

$$
\beta(1-\beta)\left\|V w_{n}-w_{n}\right\|^{2} \leq \frac{2 N\left\|w_{n}-w_{n+1}\right\|}{\beta_{n}}+\alpha_{n}\|z\|^{2} .
$$

Since $\left\|w_{n}-w_{n+1}\right\| \rightarrow 0$, we can get that

$$
\left\|V w_{n}-w_{n}\right\| \rightarrow 0
$$

Therefore,

$$
\left\|T w_{n}-w_{n}\right\| \rightarrow 0
$$

It follows that

$$
\limsup _{n \rightarrow \infty}\left\langle T w_{n}-\check{w},-\check{w}\right\rangle=\limsup _{n \rightarrow \infty}\left\langle w_{n}-\check{w},-\check{w}\right\rangle .
$$

Since $\left\{w_{n}\right\}$ converges weakly to $\check{w}$, it follows that

$$
\limsup _{n \rightarrow \infty}\left\langle T w_{n}-\check{w},-\check{w}\right\rangle \leq 0 \text {. }
$$

Similar to the proof of Theorem 4.3, we can get that the following iterative algorithm converges strongly to a solution of SEP also. Since the proof is similar to Theorem 4.3, we omit it.

Algorithm 4.4 For an arbitrary initial point $w_{0}=\left(x_{0}, y_{0}\right)$, the sequence $\left\{w_{n}=\left(x_{n}, y_{n}\right)\right\}$ is generated by the iteration

$$
w_{n+1}=\left(1-\beta_{n}\right)\left(1-\alpha_{n}\right)\left(I-\gamma G^{*} G\right) w_{n}+\beta_{n} P_{S}\left[\left(1-\alpha_{n}\right)\left(I-\gamma G^{*} G\right)\right] w_{n},
$$

i.e.,

$$
\left\{\begin{aligned}
x_{n+1}= & \left(1-\beta_{n}\right)\left(1-\alpha_{n}\right)\left[x_{n}-\gamma A^{*}\left(A x_{n}-B y_{n}\right)\right] \\
& +\beta_{n} P_{C}\left\{\left(1-\alpha_{n}\right)\left[x_{n}-\gamma A^{*}\left(A x_{n}-B y_{n}\right)\right]\right\} \\
y_{n+1}= & \left(1-\beta_{n}\right)\left(1-\alpha_{n}\right)\left[y_{n}+\gamma B^{*}\left(A x_{n}-B y_{n}\right)\right] \\
& +\beta_{n} P_{Q}\left\{\left(1-\alpha_{n}\right)\left[y_{n}+\gamma B^{*}\left(A x_{n}-B y_{n}\right)\right]\right\}
\end{aligned}\right.
$$

where $\alpha_{n}>0$ is a sequence in $(0,1)$ such that

(i) $\lim _{n \rightarrow \infty} \alpha_{n}=0, \sum_{n=0}^{\infty} \alpha_{n}=\infty$;

(ii) $\lim _{n \rightarrow \infty}\left|\alpha_{n+1}-\alpha_{n}\right|=0$;

(iii) $0<\liminf _{n \rightarrow \infty} \beta_{n} \leq \limsup _{n \rightarrow \infty} \beta_{n}<1$.

\section{Other iterative methods}

In this section, we introduce some other iterative algorithms which converge strongly to a solution of SEP.

According to Lemma 2.5, we know that $w=(x, y)$ belongs to the solution set $\Gamma$ of SEP (1.1) if and only if $w \in \operatorname{Fix}\left(P_{S}\left(I-\gamma G^{*} G\right)\right)$. Moreover, $P_{S}\left(I-\gamma G^{*} G\right)$ is a nonexpansive mapping. 
That is to say, the essence of SEP is to find a fixed point for the nonexpansive mapping $P_{S}\left(I-\gamma G^{*} G\right)$.

For the fixed point of a nonexpansive mapping, the following results have been obtained. In 1974, Ishikawa [14] gave the Ishikawa iteration as follows:

$$
\left\{\begin{array}{l}
x_{0} \in C \\
y_{n}=\left(1-\beta_{n}\right) x_{n}+\beta_{n} T x_{n}, \quad n \geq 0 \\
x_{n+1}=\left(1-\alpha_{n}\right) x_{n}+\alpha_{n} T y_{n}, \quad n \geq 0
\end{array}\right.
$$

where $x_{0} \in C$ is an arbitrary (but fixed) element in $C$, and $\left\{\alpha_{n}\right\},\left\{\beta_{n}\right\}$ are two sequences in $(0,1)$. He proved that if $0 \leq \alpha_{n} \leq \beta_{n} \leq 1, \beta_{n} \rightarrow 0, \sum_{n=1}^{\infty} \alpha_{n} \beta_{n}=\infty$, then $\left\{x_{n}\right\}$ converges strongly to a fixed point of $T$.

In 2004, Xu [15] gave the viscosity iteration for nonexpansive mappings. He considered the iteration process

$$
x_{n+1}=\alpha_{n} f\left(x_{n}\right)+\left(1-\alpha_{n}\right) T x_{n}, \quad n \geq 0,
$$

where $f$ is a contraction on $C$ and $x_{0}$ is an arbitrary (but fixed) element in $C$. He proved that if $\alpha_{n} \rightarrow 0, \sum_{n=0}^{\infty} \alpha_{n}=\infty$, either $\sum_{n=0}^{\infty}\left|\alpha_{n+1}-\alpha_{n}\right|<\infty$ or $\lim _{n \rightarrow \infty}\left(\alpha_{n+1} / \alpha_{n}\right)=1$, then $\left\{x_{n}\right\}$ converges strongly to a fixed point of $T$.

Halpern's iteration is as follows:

$$
x_{n+1}=\alpha_{n} u+\left(1-\alpha_{n}\right) T x_{n}, \quad n \geq 0,
$$

where $u \in C$ is an arbitrary (but fixed) element in $C$.

Mann's iteration method that produces a sequence $\left\{x_{n}\right\}$ via the recursive manner is as follows:

$$
x_{n+1}=\alpha_{n} x_{n}+\left(1-\alpha_{n}\right) T x_{n}, \quad n \geq 0,
$$

where the initial guess $x_{0} \in C$ is chosen arbitrarily. However, this scheme has only weak convergence even in a Hilbert space.

In 2005, Kim and Xu [16] modified Mann's iteration scheme and the modified iteration method still works in a Banach space. Let $C$ be a closed convex subset of a Banach space and $T: C \rightarrow C$ be a nonexpansive mapping such that $\operatorname{Fix}(T) \neq \emptyset$. Define $\left\{x_{n}\right\}$ in the following way:

$$
\left\{\begin{array}{l}
x_{0} \in C \\
y_{n}=\alpha_{n} x_{n}+\left(1-\alpha_{n}\right) T x_{n}, \quad n \geq 0 \\
x_{n+1}=\beta_{n} u+\left(1-\beta_{n}\right) T y_{n}, \quad n \geq 0
\end{array}\right.
$$

where $u \in C$ is an arbitrary (but fixed) element in $C$, and $\left\{\alpha_{n}\right\},\left\{\beta_{n}\right\}$ are two sequences in $(0,1)$. They proved that if $\alpha_{n} \rightarrow 0, \beta_{n} \rightarrow 0, \sum_{n=1}^{\infty} \alpha_{n}=\infty, \sum_{n=1}^{\infty} \beta_{n}=\infty$, and $\sum_{n=1}^{\infty} \mid \alpha_{n+1}-$ $\alpha_{n}\left|<\infty, \sum_{n=1}^{\infty}\right| \beta_{n+1}-\beta_{n} \mid<\infty$, then $\left\{x_{n}\right\}$ converges strongly to a fixed point of $T$.

Therefore, we have the following iterative algorithms which converge strongly to a solution of SEP. 


\section{Algorithm 5.1}

$$
\left\{\begin{array}{l}
w_{0}=\left(x_{0}, y_{0}\right) \in H=H_{1} \times H_{2}, \\
v_{n}=\left(1-\beta_{n}\right) w_{n}+\beta_{n} P_{S} T w_{n}, \quad n \geq 0, \\
w_{n+1}=\left(1-\alpha_{n}\right) w_{n}+\alpha_{n} P_{S} T v_{n}, \quad n \geq 0,
\end{array}\right.
$$

particulars:

$$
\left\{\begin{array}{l}
x_{0} \in H_{1}, y_{0} \in H_{2}, \\
z_{n}=x_{n}-\gamma A^{*}\left(A x_{n}-B y_{n}\right), \\
h_{n}=y_{n}+\gamma B^{*}\left(A x_{n}-B y_{n}\right), \\
j_{n}=x_{n}-A^{*}\left(\gamma A x_{n}-B y_{n}\right), \\
k_{n}=y_{n}+B^{*}\left(A x_{n}-\gamma B y_{n}\right), \\
x_{n+1}=\left(1-\alpha_{n}\right) x_{n}+\alpha_{n} P_{C}\left[\left(1-\beta_{n}\right) j_{n}+\beta_{n}\left(I-\gamma A^{*} A\right) P_{C} z_{n}+\beta_{n} A^{*} B P_{Q} h_{n}\right], \\
y_{n+1}=\left(1-\alpha_{n}\right) y_{n}+\alpha_{n} P_{Q}\left[\left(1-\beta_{n}\right) k_{n}+\beta_{n} B^{*} A P_{C} z_{n}+\beta_{n}\left(I-\gamma B^{*} B\right) P_{Q} h_{n}\right],
\end{array}\right.
$$

where $w_{0}=\left(x_{0}, y_{0}\right)$ is an arbitrary (but fixed) element in $H, T=I-\gamma G^{*} G$ and $\left\{\alpha_{n}\right\},\left\{\beta_{n}\right\}$ are two sequences in $(0,1)$. If $0 \leq \alpha_{n} \leq \beta_{n} \leq 1, \beta_{n} \rightarrow 0, \sum_{n=1}^{\infty} \alpha_{n} \beta_{n}=\infty$, then $\left\{w_{n}\right\}$ converges strongly to a solution of SEP.

\section{Algorithm 5.2}

$$
w_{n+1}=\alpha_{n} f\left(w_{n}\right)+\left(1-\alpha_{n}\right) P_{S} T w_{n}, \quad n \geq 0,
$$

particulars:

$$
\left\{\begin{array}{l}
x_{n+1}=\alpha_{n} P_{H_{1}} f\left(x_{n}, y_{n}\right)+\left(1-\alpha_{n}\right) P_{C}\left[x_{n}-\gamma A^{*}\left(A x_{n}-B y_{n}\right)\right] \\
y_{n+1}=\alpha_{n} P_{H_{2}} f\left(x_{n}, y_{n}\right)+\left(1-\alpha_{n}\right) P_{Q}\left[y_{n}+\gamma B^{*}\left(A x_{n}-B y_{n}\right)\right]
\end{array}\right.
$$

where $f$ is a contraction on $H=H_{1} \times H_{2}$ and $w_{0}=\left(x_{0}, y_{0}\right)$ is an arbitrary (but fixed) element in $H$, and $T=I-\gamma G^{*} G$. If $\alpha_{n} \rightarrow 0, \sum_{n=0}^{\infty} \alpha_{n}=\infty$, either $\sum_{n=0}^{\infty}\left|\alpha_{n+1}-\alpha_{n}\right|<\infty$ or $\lim _{n \rightarrow \infty}\left(\alpha_{n+1} / \alpha_{n}\right)=1$, then $\left\{w_{n}\right\}$ converges strongly to a solution of SEP.

\section{Algorithm 5.3}

$$
\left\{\begin{array}{l}
w_{0}=\left(x_{0}, y_{0}\right), u=\left(x_{1}, y_{1}\right) \in H=H_{1} \times H_{2}, \\
v_{n}=\alpha_{n} w_{n}+\left(1-\alpha_{n}\right) P_{S} T w_{n}, \quad n \geq 0, \\
w_{n+1}=\beta_{n} u+\left(1-\beta_{n}\right) P_{S} T v_{n}, \quad n \geq 0,
\end{array}\right.
$$

particulars:

$$
\left\{\begin{array}{l}
x_{0}, x_{1} \in H_{1}, y_{0}, y_{1} \in H_{2}, \\
z_{n}=x_{n}-\gamma A^{*}\left(A x_{n}-B y_{n}\right), \\
h_{n}=y_{n}+\gamma B^{*}\left(A x_{n}-B y_{n}\right), \\
j_{n}=x_{n}-A^{*}\left(\gamma A x_{n}-B y_{n}\right), \\
k_{n}=y_{n}+B^{*}\left(A x_{n}-\gamma B y_{n}\right), \\
x_{n+1}=\alpha_{n} x_{1}+\left(1-\alpha_{n}\right) P_{C}\left[\beta_{n} j_{n}+\left(1-\beta_{n}\right)\left(I-\gamma A^{*} A\right) P_{C} z_{n}+\left(1-\beta_{n}\right) A^{*} B P_{Q} h_{n}\right], \\
y_{n+1}=\alpha_{n} y_{1}+\left(1-\alpha_{n}\right) P_{Q}\left[\beta_{n} k_{n}+\left(1-\beta_{n}\right) B^{*} A P_{C} z_{n}+\left(1-\beta_{n}\right)\left(I-\gamma B^{*} B\right) P_{Q} h_{n}\right],
\end{array}\right.
$$


where $u, w_{0}$ are arbitrary (but fixed) elements in $H, T=I-\gamma G^{*} G$, and $\left\{\alpha_{n}\right\},\left\{\beta_{n}\right\}$ are two sequences in $(0,1)$. They proved that if $\alpha_{n} \rightarrow 0, \beta_{n} \rightarrow 0, \sum_{n=1}^{\infty} \alpha_{n}=\infty, \sum_{n=1}^{\infty} \beta_{n}=\infty$ and $\sum_{n=1}^{\infty}\left|\alpha_{n+1}-\alpha_{n}\right|<\infty, \sum_{n=1}^{\infty}\left|\beta_{n+1}-\beta_{n}\right|<\infty$, then $\left\{w_{n}\right\}$ converges strongly to a solution of SEP.

\section{Competing interests}

The authors declare that they have no competing interests.

\section{Authors' contributions}

The main idea of this paper was proposed by $L S, R C$ and $Y W$ prepared the manuscript initially and performed all the steps of the proofs in this research. All authors read and approved the final manuscript.

\section{Author details}

'Department of Mathematics, Tianjin Polytechnic University, Tianjin, 300387, P.R. China. ${ }^{2}$ Tianjin Vocational Institute, Tianjin, 300410, P.R. China.

\section{Acknowledgements}

This research was supported by NSFC Grants No:11071279; No:11226125; No:11301379.

Received: 11 September 2014 Accepted: 12 November 2014 Published: 02 Dec 2014

\section{References}

1. Censor, Y, Elfving, T: A multiprojection algorithm using Bregman projections in a product space. Numer. Algorithms 8(2-4), 221-239 (1994)

2. Byrne, C: Iterative oblique projection onto convex sets and the split feasibility problem. Inverse Problems 18(2), 441-453 (2002)

3. Byrne, $C:$ A unified treatment of some iterative algorithms in signal processing and image reconstruction. Inverse Problems 20(1), 103-120 (2004)

4. Qu, B, Xiu, N: A note on the CQ algorithm for the split feasibility problem. Inverse Problems 21(5), 1655-1665 (2005)

5. Xu, H-K: A variable Krasnosel'skii-Mann algorithm and the multiple-set split feasibility problem. Inverse Problems 22(6), 2021-2034 (2006)

6. Yang, Q: The relaxed CQ algorithm solving the split feasibility problem. Inverse Problems 20(4), 1261-1266 (2004)

7. Yang, Q, Zhao, J: Generalized KM theorems and their applications. Inverse Problems 22(3), 833-844 (2006)

8. Moudafi, A: A relaxed alternating CQ-algorithms for convex feasibility problems. Nonlinear Anal., Theory Methods Appl. 79, 117-121 (2013)

9. Geobel, K, Kirk, WA: Topics in Metric Fixed Point Theory. Cambridge Studies in Advanced Mathematics, vol. 28 Cambridge University Press, Cambridge (1990)

10. Geobel, K, Reich, S: Uniform Convexity, Nonexpansive Mappings, and Hyperbolic Geometry. Dekker, New York (1984)

11. Aoyama, K, Kimura, Y, Takahashi, W, Toyoda, M: Approximation of common fixed points of a countable family of nonexpansive mappings in a Banach space. Nonlinear Anal., Theory Methods Appl. 67(8), 2350-2360 (2007)

12. Suzuki, T: Strong convergence theorems for infinite families of nonexpansive mappings in general Banach space. Fixed Point Theory Appl. 1, 103-123 (2005)

13. Engl, HW, Hanke, M, Neubauer, A: Regularization of Inverse Problems. Mathematics and Its Applications, vol. 375. Kluwer Academic, Dordrecht (1996)

14. Ishikawa, S: Fixed points by a new iteration method. Proc. Am. Math. Soc. 44, 147-150 (1974)

15. Xu, H-K: Viscosity approximation methods for nonexpansive mappings. J. Math. Anal. Appl. 298, 279-291 (2004)

16. Kim, TH, Xu, H-K: Strong convergence of modified Mann iterations. Nonlinear Anal. 61, 51-60 (2005)

10.1186/1029-242X-2014-478

Cite this article as: Shi et al.: Strong convergence of iterative algorithms for the split equality problem. Journal of Inequalities and Applications 2014, 2014:478 